\title{
СОЗНАТЕЛЬНОЕ И БЕССОЗНАТЕЛЬНОЕ В ПОЛИТИКЕ (ПЛАТОН И «ПЕЩЕРНЫЕ ЛЮДИ»)
}

\author{
В. И. Буренко \\ Московский гуманитарный университет
}

Аннотащия: В статье на материалах «символа пещеры» Платона представлена трактовка сознательного и бессознательного в политике.

Текст доклада автора на Всероссийской научной конференции «Культура между Логосом и Мифом: к проблеме бессознательного (к 80-летию А. Э. Воскобойникова)», которая прошла в Московском гуманитарном университете 26-27 октября 2017 года.

Ключевые слова: политическая модернизация; свобода; демократия; авторитарный транзит; медиа-манипулирование; рациональное; иррациональное; подданническая культура; Платон

\section{THE CONSCIOUS AND THE UNCONSCIOUS IN POLITICS (PLATO AND THE "CAVE PEOPLE")}

\author{
V. I. Burenko \\ Moscow University for the Humanities
}

Аннотация: The paper is based on the material of Plato's "symbol of the cave" and presents an interpretation of the conscious and unconscious in politics.

The text of the author's speech at the All-Russian Scientific Conference "Culture between Logos and Myth: on the Issue of the Unconscious (dedicated to the 80th anniversary of A. E. Voskoboynikov)", which was held at Moscow University for the Humanities on 26-27 October 2017.

Ключевые слова: political modernisation; freedom; democracy; authoritative transition; media-manipulation; rational; irrational; subject culture; Plato

Классические научные произведения - это не только образец для тех, кто продолжает работать в науке, но это и произведения, которые спустя века остаются современными, позволяют интерпретировать те или иные события, происходящие в последующие эпохи. Работы многих древнегреческих авторов являют образец классической литературы. Читатель XXI века может найти много поучительного в философских и политических работах Платона, Аристотеля, Полибия и др. А для исследователя современности 
многие идеи великих греческих мыслителей являются до сих пор методологически значимыми.

В данной статье нас будет интересовать современная Россия в контексте некоторых идей Платона. Греческий мыслитель одним из первых стал анализировать политические процессы, которые в современной литературе называют политической модернизацией. Так, платоновская классификация государств заканчивается следующим теоретически важным выводом: «...тирания возникает, конечно, не из какого иного строя, как из демо-кратии; иначе говоря, из крайней свободы возникает величайшее и жесточайшее рабство» (Платон, 1994: 352) .

Этот авторитарный транзит: «из демократии возникает тирания»в политической истории человечества повторялся много раз. Английская революция, которая содержала демократические цели, - предоставление свобод для формирующегося слоя предпринимателей, расширение полномочий парламента и др., - завершилась казнью короля и диктатурой Оливера Кромвеля. Великая французская революция, на знамёнах которой были начертаны демократические лозунги «Свобода, Равенство, Братство», завершилась установлением диктатуры Наполеона. Две российские революции 1917 г. сопровождаемые демократическими обещаниями, трансформировались в сталинскую диктатуру. За демократизацией в Германии в 20-е годы XX века последовала гитлеровская диктатура. Демократические преобразования в Чили в 1970-1973 гг. под руководством президента С. Альенде вызвали сопротивление национальных и международных олигархических структур и в результате армейского путча власть в стране захватила военная хунта во главе с генералом Пиночетом.

Демократические начинания в России 1990-х годов сменяются нарастанием авторитарных тенденций в последние полтора десятилетия. Как пишет член-корреспондент РАН К. И. Микульский «нынешний российский авторитаризм блокирует разрешение системных противоречий, препятствует демократизации общественной жизни. Сама сущность нынешней модели делает реальной перспективу развертывания государственного насилия над обществом, углубления антидемократической ориентации авторитаризма» (Микульский, 2011: Электр. ресурс).

В качестве эмпирического материала можно более конкретно исследовать этот исторический тренд, но, пожалуй, отмеченного достаточно, чтобы сделать вывод: история много раз наказывала те народы, которые не учили её уроков и не усваивали идеи великих учителей человечества. И вместо стремления к свободе история погружала эти народы в свирепое рабство. Народы оказывались лёгкой добычей в руках различного рода «манипуляторов», которые конструировали из человеческой массы необходимый им 
материал. И очень часто это происходило при помощи этой самой массы. Как писал немецкий поэт и драматург Б. Брехт: «Шагают бараны в ряд, Бьют в барабаны, Кожу для барабанов, Сами дают бараны».

В связи с юбилеем нашего коллеги, доктора философских наук, профессора А. Э. Воскобойникова, научный интерес которого сконцентрирован на проблемах сознательного и бессознательного в человеке и обществе, мне хотелось бы поразмышлять о сложностях рационального осмысления реальных процессов массовым сознанием и некоторых факторах исторически повторяющегося тренда погружения народов в несвободу.

Следует подчеркнуть, что сложности взаимодействия сознательного и бессознательного в процессе познания реальности были поставлены уже Платоном в знаменитом «символе пещеры». Сокращая, насколько это возможно для дальнейшего понимания, воспроизведём этот небольшой диалог из седьмой главы книги «Государство».

— «После этого, — сказал я, — ты можешь уподобить нашу человеческую природу в отношении просвещенности и непросвещенности вот какому состоянию... посмотри-ка: люди как бы находятся в подземном жилище наподобие пещеры, ...С малых лет у них там на ногах и на шее оковы, так что людям не двинуться с места, и видят они только то, что у них прямо перед глазами, ибо повернуть голову они не могут из-за этих оков. Люди обращены спиной к свету, исходящему от огня, который горит далеко в вышине, а между огнем и узниками проходит верхняя дорога, огражденная - глянь-ка, невысокой стеной вроде той ширмы, за которой фокусники помещают своих помощников,

Прежде всего, разве ты думаешь, что, находясь в таком положе-нии, люди что-нибудь видят, свое ли или чужое, кроме теней, отбрасываемых огнем на расположенную перед ними стену пещеры?

- Такие узники целиком и полностью принимали бы за истину тени проносимых мимо предметов.

- Это совершенно неизбежно

- Понаблюдай же их освобождение от оков неразумия и исцеление от него, иначе говоря, как бы это всё у них происходило, если бы с ними естественным путём случилось нечто подобное

— И как ты думаешь, что он скажет, когда ему начнут говорить, что раньше он видел пустяки, а теперь, приблизившись к бытию и обратившись к более подлинному, он мог бы обрести правильный взгляд? Да ещё если станут указывать на ту или иную мелькающую перед ним вещь и задавать вопрос, что это такое, и вдобавок заставят его отвечать! Не считаешь ли ты, что это крайне его затруднит и он подумает, будто гораздо больше правды в том, что он видел раньше, чем в том, что ему показывают теперь?

- Конечно, он так подумает.

- Если же кто станет насильно тащить его по крутизне вверх, в гору и не отпустит пока не извлечет его на солнечный свет, разве он не будет страдать 
и не возмутится таким насилием? А когда бы он вышел на свет, глаза его настолько были бы поражены сиянием, что он не мог бы разглядеть ни одного предмета из тех, о подлинности которых ему теперь говорят.

- Да, так сразу он этого бы не смог.

- Тут нужна привычка, раз ему предстоит увидеть всё то, что там, на веру. Начинать надо с самого легкого: сперва смотреть на тени, затем - на отражения в воде людей и различных предметов, а уж потом - на самые вещи; при этом то, что на небе, и самое небо ему легче было бы видеть не днем, а ночью, то есть смотреть на звездный свет и Луну, а не на Солнце и, его свет.

- Вспомнив свое прежнее жилище, тамошнюю премудрость и сотоварищей по заключению, разве не сочтет он блаженством перемену своего положения и разве не пожалеет своих друзей?

- И даже очень.

- Обдумай еще и вот что: если бы такой человек опять спустился туда и сел бы на то же самое место, разве не были бы его глаза охвачены мраком при таком внезапном уходе от света Солнца.

- Конечно.

- А если бы ему снова пришлось состязаться с этими вечными узниками, разбирая значение тех теней? Пока его зрение не притупится и глаза не привыкнут - а на это потребовалось бы немалое время, - разве не казался бы он смешон? О нем стали бы говорить, что из своего восхождения он вернулся с испорченным зрением, а значит, не стоит даже и пытаться идти ввысь. А кто принялся бы освобождать узников, чтобы повести их ввысь, того разве они не убили бы попадись он им в руки?

- Непременно убили бы.

- Так вот, дорогой мой Главкон, это уподобление следует применить ко всему, что было сказано ранее: область, охватываемая зрением, подобна тюремному жилищу, а свет от огня уподобляется в ней мощи Солнца. Восхождение и созерцание вещей, находящихся в вышине, - это подъем души в область умопостигаемого» (Платон, 1994: 295-298).

По поводу мифа о пещере в истории философии возникало множество интерпретаций. Некоторые трактовки мифа говорят о том, что Платон таким образом отразил сложности процесса познания. Его люди в пещере ещё не пробились к свету знаний и живут под знаком чувства, под знаком того, что развёртывается перед их взором непосредственно, там, на стене пещеры. Да и сам Платон, завершая изложение мифа о пещере, пишет: «область, охватываемая зрением, подобна тюремному жилищу, а свет от огня уподобляется в ней мощи Солнца. Восхождение и созерцание вещей, находящихся в вышине, - это подъем души в область умопостигаемого».

Итальянские исследователи Дж. Реале и А. Антисери, видят в этом мифе политический подтекст. «Платон говорит о возможном возвращении в пещеру того, кто однажды был освобождён. Вернуться и вывести к сво- 
Научные труды Московского гуманитарного университета 2018 № 3

боде тех, с которыми провёл долгие годы рабства. Несомненно, это возвращение философа-политика, единственное желание которого - созерцание истины. Возникает вопрос: что ждёт спустившегося вновь из царства света в царство теней? Его не поймут, пока он не адаптируется к старым привычкам. Принеся с собой возмущение, он рискует навлечь на себя гнев людей, предпочитающих блаженное неведение. Он рискует и большим, - быть убитым как Сократ» (Реале, Антисери, 1994: 130).

Метод рационального прочтения политических мифов и иносказаний, который был использован в данной статье, получил название политической демифологизации (Полосин, 1999: 26-30). Явления мифологизации и демифологизации в политическом пространстве, методы их исследования обстоятельно рассмотрены герменевтикой, а также раскрыты в работах П. Бурдье, посвящённых символической власти и политическому фетишизму. Опираясь на эти исследования, позволю себе ещё одну интерпретацию символа пещеры, навеянную наблюдениями за процессами конструирования мифов в современной политике.

Платон, на мой взгляд, пишет о сложностях политической модернизации, связанных, прежде всего с изменением самого человека, с борьбой за человека, с мучительным переходом человека от несвободы к свободе и связанной с этим необходимостью взять на себя ответственность за самого себя, за своё будущее, за будущее своей страны.

«Оковы» в платоновском мифе - это не только «оковы неразумия», это «тамошняя премудрость» от которой мучительно и тяжело отказаться. Здесь разговор не столько о сложности движения от незнания к знанию, от чувственного к рациональному, сколько о борьбе за освобождение от «тамошней премудрости», от оков традиции, закрепляющей политическое рабство. Его, побывавшего на свободе и вкусившего дух истины, - пишет Платон, - «не поймут, пока он не адаптируется к старым привычкам». Старые привычки это уютные привычки несвободы. Это привычки политического рабства. Во времена Платона греки были свободны в экономическом плане (несвободны были рабы), но в политическом плане несвободны были и граждане полиса. Древнегреческая демократия - это была тирания большинства. Идея индивидуальной свободы была ещё неведома древним грекам. Это убедительно показал в своей работе «О свободе у древних в её сравнении со свободой у современных людей» Б. Констан. Свобода у древних - это господство воли большинства, это свобода, скованная волей большинства. Платоновский миф пещеры и многие работы великого философа являют собой осмысление начального периода перехода человечества от доиндивидуалистической или общинно-племенной эпохи к эпохе индивидуальной свободы. Для многих народов этот переход продолжается ещё и сегодня. И каждый народ осуществляет 
его в своё время и по своему, обнаруживая, однако, при этом много общего.

Начало рассмотрения проблем индивидуальной свободы как важнейшей ценности политической модернизации можно найти уже в первых работах Платона. Так в «Апологии Сократа» есть два примечательных тезиса. В одном из них Сократ, выступая перед судьями, говорит: «нет такого человека, который мог бы уцелеть, если бы стал откровенно противиться вам или какому-нибудь другому большинству» (Платон, 1968: 101) и, однако, в другом положении Сократ утверждает: «Я вам предан афиняне, и люблю вас, но слушаться буду скорее бога, чем вас, и пока я дышу и остаюсь в силах, не перестану философствовать...» (там же: 98).

Мнение большинства, а также закреплённые в мифах «тамошние пре-мудрости» - вот что развёртывается на стене перед узниками пещеры. И против этого мнения, ради свободы мыслить, восстаёт Сократ. Сам Платон, как свидетельствуют его позднейшие работы, не был почитателем идеи свободы. Авторитетные исследователи, указывая на мельчайшую регламентацию всей жизни платоновского полиса посредством власти и закона, отмечают, что «платонизм в социальном смысле есть философия монахов, полиции и рабов-послушников» (Лосев, 1993: 823, 828), что «программа греческого мыслителя не выходит за рамки тоталитаризма» (Поппер, 1992: 124).

Вместе с тем, случай Сократа (кейс) стал для Платона эмпирическим материалом, при анализе которого свобода философствования, свобода мысли были обозначены в качестве важнейшей ценности того периода и ставшие исходной ценностью всей дальнейшей истории, расширяясь в последующие века до идей свободы творчества, свободной личности, свободной индивидуальности. Начиная с Нового времени, политическая мысль и политическая модернизация вращались вокруг идеи человека как высшей ценности исторического процесса и поиска путей (институтов, механизмов) практического воплощения этой идеи.

Но политическая история показывает, что мнение большинства это не только результат сложности процесса познания и трудности расставания с отжившей традицией, застывшей в мифах. Мнение большинства - это ещё и результат целенаправленного конструирования и «подмораживания» этого мнения и заблуждения и беспощадной борьбы против тех, кто расколдовывает эти заблуждения. Не случайно Платон говорит в своём мифе о ширме, «за которой фокусники помещают своих помощников» и об убийстве тех, «кто принялся бы освобождать узников».

XX век был веком невиданной в истории человечества решительной схватки идей свободы и несвободы, рационального и иррационального. Появилась, пишет Э. Фромм о фашизме, политическая система, «которая, по существу, опирается отнюдь не на рациональные силы человеческого личного 
Научные труды Московского гуманитарного университета 2018 № 3

интереса. Она пробуждает в человеке такие дьявольские силы, в существование которых мы вообще не верили либо считали их давным-давно исчезнувшими» (Фромм, 1995: 16). Появились политические силы, оформившиеся в государства в облике фашизма, нацизма и т. п., которые, спекулируя на иррациональных началах в человеке, уничтожали индивидуальную свободу. «Фашистская концепция, - заявил в своей доктрине фашизма Б. Муссолини, подчеркивает значение государства и принимает индивида лишь настолько, насколько его интересы совпадают с интересами государства» (там же). Появляются идеологи, в том числе в современной России, которые поднимают иррациональное знамя борьбы против человека и его свободы. Русский национализм должен быть единственной и тотальной идеологией, могущей иметь свои различные версии и уровни, но всегда остающейся постоянной во всём, что касается постановки категории «нации» над категорией «индивидуальности». В конечном счёте, должен быть выдвинут радикальный лозунг: «нация - всё, индивидуум - ничто» (там же). Учебники для студентов с такими текстами, издаются многотысячными тиражами, и авторы этих идей, пользуясь демократическим завоеванием - «свободой слова», - ведут борьбу против свободы.

$\mathrm{XX}$ век боролся против свободы через физическое насилие над личностью и с помощью обращения к тёмным сторонам массовой психологии. Коммуникативная сторона властных отношений всегда была насыщена психологической окраской. Но внимание исследователей к иррациональным аспектам властвования резко активизировалось вместе с процессом вторжения масс в политику, трансформацией политики в массовое явление. Работы 3. Фрейда, Г. Лебона, Г. Тарда, К. Юнга, Э. Фромма, С. Московичи и продолжателя их дела, нашего коллегии и юбиляра А. Э. Воскобойникова (Воскобойников, 1997) раскрывают различные стороны и уровни психической жизни людей, сознательное и бессознательное в жизни, как отдельного человека, так и особенности его массового поведения. Было показано, что иррациональное это постоянный фактор политики. Тем самым были похоронены надежды века Просвещения на рациональное переустройство мира. Понимание политики и общества изменилось в результате осознания следующего факта: любые узы, удерживающие вместе человеческие сообщества, не являются следствием рационального расчета их отдельных представителей (Хобсбаум, 2015: Электр. ресурс). Было показано, что иррациональное в политике, (в том числе политическая мифология от Платона до современности), выполняет функцию как сохранения власти и упрочения социального порядка, так и поддержания хаоса и страха в обществе ради сохранения у власти тирании.

XXI век - это век борьбы против свободы в первую очередь через психическое насилие. Обращение к самым тёмным сторонам массового сознания 
многократно усиливается возможностями технического арсенала Современности. Сегодня обращение к бессознательному, мобилизация бессознательного стало одной из самых эффективных политических технологий.

В современную эпоху телевидение представляет собой платоновскую стену пещеры, «телевидение стало основным видом коммуникации» (Кастельс, 2000: 317). Стена пещеры и тени, мелькающие на ней — это сегодня не что иное, как телевизионная картина, выполняющая функцию коммуникации между властью и обществом. Платоновский миф пещеры раскрывает социально-политические функции мифа как средства массовой коммуникации и как средства манипуляции узниками пещеры со стороны тех, кто там, наверху «пещеры».

Власть разговаривает сегодня с народом через телевидение, и языком телевидения. Язык телевидения заключает в себе огромные возможности обращения к архетипам, к эмоциональной стороне человеческого сознания, создания и внедрения в массовое сознание политических мифов.

Телевидение стало важнейшим ресурсом властвования в современной России. Особая значимость телевидения как инструмента власти обусловлена тем, что массовые телеканалы, которые ежедневно смотрят десятки миллионов россиян, прямо или опосредованно находятся под контролем государства. Занимая господствующие позиции в информационном пространстве, государство обладает монополией на интерпретацию тех или иных общественно значимых проблем. Властная интерпретация происходящих событий становится господствующей. Альтернативных интерпретаций граждане не слышат. «Прежде всего, - говорит Платон в своём мифе, - разве ты думаешь, что находясь в таком положении, люди что-нибудь видят, кроме теней, отбрасываемых огнем на расположенную перед ними стену пещеры?»

В этой связи, можно сказать, что в современной России нет общественного мнения, а есть мнение властвующих сил, инкорпорированное в общественное сознание. Общественное мнение сегодня - это свободно коммуницирующие мнения различных групп и слоев общества, образующие таким образом мнение сообщества граждан. Но как подчёркивал М. Кастельс «ключевая проблема состоит в том, что на данный момент СМИ представляют собой однонаправленную коммуникационную систему; поэтому реального процесса коммуникации ...при интерпретации сообщений нет» (там же: 321). Крупнейший знаток состояния дел на российском телевидении В. Познер так оценил сложившуюся ситуацию: «У нас на телевидении, да и не только на телевидении не существует свободы слова. Во время парламентских и президентских выборов были вещи совершенно запрещенные: о том нельзя говорить, это нельзя показывать, того нельзя приглашать. Получается, что законы и мнения различных руководителей оказы- 
Научные труды Московского гуманитарного университета 2018 № 3

ваются выше Основного закона, Конституции РФ» (Познер ... 2008, Электр. ресурс). Это, (как и процитированное выше положение М. Кастельса) было сказано более десяти лет назад, но за прошедшее время ситуация не изменилась, лишь «фокусники и их помощники» стали более изощрёнными в деле манипулирования массовым сознанием и поведением. «Хотя влияние телевидения на политический выбор весьма разнообразно, политика и политики, не имеющие выхода на телевидение в развитых обществах, просто не имеют шанса получить поддержку населения, поскольку люди получают информацию из СМИ, где телевидение занимает ведущее место» (Кастельс, 2000: 322). Современной разновидностью легитимации власти становится медиа-манипулятивная «легитимация».

И если практикующие социологи проводят сегодня в России исследования, то они измеряют эффективность государственного телевидения в деле индоктринации в массовое сознание взглядов властвующих сил. Эффективность телевизионной индоктринации, фиксируемая социологами, может быть измеряема объёмом и скоростью смены оценок тех или иных событий в массовом сознании россиян, вслед за изменениями официальных оценок этих событий, ретранслируемых массовыми СМИ. Так, очень быстро меняется отношение россиян к политическим фигурам. В бытность мэром Ю. Лужков неизменно получал высокую оценку своей работы со стороны федеральных властей и, соответственно, москвичей. Но как только он был отправлен в отставку, опрос, проведенный исследовательским центром рекрутингового портала Superjob.ru, выявил, что более половины столичных жителей (59\%) одобряют решение федеральных властей об отставке Лужкова (Скибюк, 2010, Электр. ресурс). На шкале «друг-враг» флюгер общественного мнения очень быстро менял направление в последние годы при оценке отношений «Россия - Украина», «Россия - Турция». Так, если в январе 2014 года на вопрос «Как вы в целом относитесь сейчас к Украине?» ответы россиян распределились так (в \%): очень хорошо - 6; в основном хорошо - 60; в основном плохо -22 ; очень плохо -4 ; затруднились ответить - 9, то через полгода, в июле 2014, года ситуация кардинально изменилась и выглядела так: очень хорошо - 3; в основном хорошо - 30; в основном плохо - 30; очень плохо - 25; затруднились ответить -13 (Цветкова, 2014: Электр. ресурс).

Принципиально, но не так быстро изменялась в массовом сознании оценка отношений «Россия - Европа», «Россия - США». Все эти качественные изменения массового сознания происходили вслед за изменением официальной политики и вместе с этим, массированной телевизионной агрессией, направленной на изменение общественного мнения россиян. Испытанным и эффективным инструментом достижения необходимого 
результата выступает искусственное нагнетание ситуации враждебного окружения, в котором оказывается Россия и поиски внутренних врагов. Актуализация образа врага в массовом сознании стала одной из особенностей политического и информационного мейнстрима в современной России. А в пространстве политического поведения это ведёт к росту радикального национализма и ксенофобии, особенно в молодёжной среде (Евгеньева, Селезнева, 2007: 88; Евгеньева, Селезнева, 2017). Против тех же, кто сеет возмущение в среде «пещерных людей», развёртывается беспощадная борьба. Им приклеивают ярлыки «предателей Родины», «иностранных агентов», «пятой колонны» и в современной России их, иногда, убивают.

Конструирование враждебного окружения, как правило, объединяет население вокруг власти, способствует ещё большему укреплению патерналистски-подданнической культуры россиян, некритическому восприятию всего того, что пишет власть на «стене пещеры». Таким образом, формируется патерналистски подданническое «демократическое большинство». Механизм консервации отживших мнений и заблуждений манипулируемого большинства оставляет содержание платоновского «символа пещеры».

Политическая история, и особенно история Германии в XX веке и постсоветской России в конце XX - начале XXI в., позволяют делать вывод о том, что современная демократия - это нечто большое, нежели мнение большинства. Демократия «может отстоять свои позиции, только если располагает действенными институтами, способными воспрепятствовать злоупотреблению властью, в том числе большинством граждан. Там, где элиты и большинство населения не разделяют этого убеждения, даже самая демократическая конституция не в состоянии оказать своё позитивное воздействие» (Любин, 2013: 182). Следовательно, для становления и укрепления демократии необходима взаимосвязь, а затем и синтез трёх элементов: действенных институтов, убеждённости элиты и большинства населения в преимуществах демократии.

За четверть века ни один из этих элементов современной демократии в России не сложился. В контексте обсуждаемых в этой статье проблем важны результаты многолетних социологических исследований «Левада-центра» по теме советского и современного российского человека, которые открыли важную особенность. Вместо подтверждения первоначальной гипотезы о советском человеке как «уходящей натуре» эти исследования показали, что «сам по себе тип советского человека никуда не исчезает» (Гудков, 2016: Электр. ресурс).

Пришлось признать, - делают вывод исследователи «Левада-центра», - что «дело не в том, чего хотят и как ведут себя молодые люди, а что с ними делают существующие социальные институты, в рамки которых 
Научные труды Московского гуманитарного университета 2018 № 3

молодёжь так или иначе должна вписаться, принять их и жить по их правилам. Основные механизмы воспроизводства этого человека обеспечены сохранением базовых институтов тоталитарной системы (даже после всех модификаций или их рекомбинации). Это вертикаль власти, неподконтрольная обществу, зависимый от администрации президента суд, политическая полиция, массовая мобилизация и призывная армия, лагерная зона, отсутствие самоуправления, псевдопарламент и, наконец, почти не изменившаяся с советских времён массовая школа, воспроизводящая прежние стандарты обучения» (там же).

Главные политические характеристики этой «неуходящей натуры»государственный патернализм, властецентризм, имперский синдром и т. п. Агрессивная, за пределами морали, эксплуатация этих иррациональных, архаичных структур сознания пронизывает содержание новостных и политических шоу-программ российского телевидения в последние годы. Платоновские «пещерные люди» - это сегодня продукт целенаправленного медиа-манипулирования сознанием и поведением населения с целью закрепления в нём послушной патерналистски-подданнической культуры как опоры сложившегося режима. «Реформирование» советской идентичности осуществляется возвратом в прошлое, но не продвижением в будущее. Так, консервируя политическую культуру прошлого, господствующие силы стремятся монопольно и окончательно закрепить за собой властные и экономические преференции. Не создание новых институтов, и не закрепление законодательством прав и привилегий новых господствующих сил, а принятие массовым сознанием новых правил игры будет свидетельствовать о завершении постсоциалистической трансформации.

Итак, социальная борьба продолжается. «Конец истории» - это очередной миф. И в XXI веке социальные конфликты не исчезнут, сознательное и бессознательное будет сопровождать эти конфликты. Но социальная борьба будет становиться всё более публичной и будет развёртываться, в том числе между новейшими информационными технологиями и властью за влияние на «стене пещеры». Современные информационные технологии не поддаются монополизации, они расширяют возможности демифологизации реальных процессов, власть же стремиться мифологизировать политические процессы. А там, наверху «пещеры», за «ширмой», будут сталкиваться реальные интересы тех сил, которые стремятся сохранить существующий порядок отношений власти и собственности и тех сил, которые этот порядок стремятся изменить с целью утверждения новой «справедливости». Так продолжается история.

Каково же место философа и философии в этой борьбе? Ответим словами известного исследователя массовой культуры, немецкого философа и 
социолога Макса Хоркхаймера: «Истиная социальная функция философии заключается в критике существующего. Главной целью этой критики является воспрепятствовать тому, чтобы человек затерялся в тех идеях и моделях поведения, которые внушает ему общество в его теперешней организации» (Horkheimer, 1974: 282).

\section{СПИСОК ЛИТЕРАТУРЫ}

Воскобойников, А. Э. (1997) Бессознательное и сознательное в человеке. М. : Институт молодежи.

Гудков, Л. (2016) Повесть о советском человеке [Электронный ресурс] // Ведомости. 28 декабря. URL: https://www.vedomosti.ru/opinion/ articles/2016/12/28/671519-povest-o-sovetskom (дата обращения: 12.12.2017).

Евгеньева, Т. В., Селезнёва, А. В. (2007) Образ врага как фактор формирования национальной идентичности современной российской молодёжи // Полития. № 3. С. 83-92.

Евгеньева, Т. В., Селезнёва, А. В. (2017) Трансформация национально-государственной идентичности российской молодёжи в постсоветский период: ценностные основания и символические репрезентации // Полития. №4. C. 48-64.

Кастельс, М. (2000) Информационная эпоха. М. : ГУ-ВШЭ.

Лосев, А. Ф. (1993) Очерки античного символизма. М. : Мысль. 962 с.

Любин, В. П. (2013) О неготовности постимперского общества к демократии (Винклер Г. А. Веймар 1918 - 1933: История первой немецкой демократии / Пер. с нем. Е. Е. Земсковой, А. И. Савина. - М.: Росспэн. 2013) // Полития. № 4. С. 176-190.

Микульский, К. И. (2011) Кризис российского авторитаризма [Электронный ресурс] // Независимая газета. 6 апреля. URL: http://www.ng.ru/ ideas/2011-04-06/5_crisis.html (дата обращения: 12.12.2017).

Платон (1968) Сочинения в 3-х т. М. : Мысль. Т. 1.

Платон (1994) Собрание сочинений : в 4-х т. / пер. с древнегр. М. : Мысль. T. $3.654 \mathrm{c}$.

Познер рассказал о цензуре на телевидении (2008) [Электронный ресурс] // Газета.Ру. 27 марта. URL: https://www.gazeta.ru/politics/2008/03/27 kz_2678873.shtml (дата обращения: 12.12.2008).

Полосин, В. (1999) Миф, религия, государство. М. : Ладомир. 440 с.

Поппер, К. (1992) Открытое общество и его враги : в 2-х т. М. : Феникс, Международный фонд «Культурная инициатива». Т. 1.

Реале, Дж., Антисери, Д. (1994) Западная философия от истоков до наших дней. І. Античность. СПб. : ТОО ТК «Петрополис». 
Скибюк, С. (2010) Москвичи без Лужкова [Электронный ресурс] // Антикризисная клиника. URL: http://73anticrizis.ru/content/view/1703/2/ (дата обращения 12.11. 2017).

Фромм, Э. (1995) Бегство от свободы. М.

Хобсбаум, Э. (2015) Массовое производство традиций: Европа, 1870-1914 [Электронный ресурс] // Неприкосновенный запас. № 6. URL: http://magazines.russ.ru/nz/2015/104/massovoe-proizvodstvo-tradicijevropa-18701914.html (дата обращения 12.11. 2017).

Цветкова, Р. (2014) Эрозия обоюдной ненависти [Электронный ресурс] // Независимая газета (НГ-Политика). 16 сентября. URL: http://www.ng.ru/ ng_politics/2014-09-16/9_erosia.html (дата обращения: 12.12.2017).

Horkheimer, M. (1974) Die gesellschaftlichen Funktion der Philosophie. Frankfurt am Main.

Дата поступления: 30.12.2017 2.

Буренко Владимир Иванович - доктор политических наук, профессор, профессор кафедры философии, культурологии и политологии Московского гуманитарного университета. Адрес: 111395, Россия, г. Москва, ул. Юности, д. 5. Тел.: +7 (499) 374-51-11. Эл. адрес: vburenko@mail.ru

\section{Для цитирования:}

Буренко В. И. Сознательное и бессознательное в политике (Платон и «пещерные люди»][Электронный ресурс] // Научные труды Московского гуманитарного университета. 2018. № 3. URL: http://journals.mosgu.ru/trudy/ article/view/741 (дата обращения: дд.мм.гг.). DOI: 10.17805/trudy.2018.3.4 